\title{
O TRABALHO EM ANDRÉ GORZ: três reflexões, uma problemática ${ }^{1}$
}

\author{
Henrique Amorim*
}

\begin{abstract}
Há aproximadamente dez anos André Gorz morreu, deixando ideias estimulantes sobre os limites e a necessidade de superação ou desconstrução da sociedade capitalista. Sempre atento às transformações sociais, Gorz chegou, em certos momentos, a sintetizar tudo que havia de mais profundo e crítico na teoria social. Entretanto, é possível observar, em sua obra, uma oscilação em relação ao lugar social que o trabalho ocupa. O lugar do trabalho parece mudar em função do desenvolvimento das forças produtivas. Assim, a análise do movimento social do trabalho na sociedade capitalista, realizada por Gorz, permanece prisioneira de uma determinação tecnológica e de um conceito de trabalho limitado ao universo produtivo das qualificações profissionais. Neste artigo, tenho como objetivo problematizar a concepção de trabalho exposta por Gorz em três de suas principais obras: Estratégia Operária e Neocapitalismo (1964), Adeus ao Proletariado (1980) e O Imaterial (2003), demonstrando como a teoria social e as alternativas políticas desenvolvidas por Gorz mudam vis-à-vis o lugar social ocupado pelo trabalho nessas obras.

PAlavras-chave: André Gorz. Trabalho. Humanismo. Determinismo. Trabalho imaterial.
\end{abstract}

\section{INTRODUÇÃO}

Há aproximadamente dez anos, no dia 22 de setembro de 2007, André Gorz morreu, deixando ideias estimulantes sobre a estruturação, os limites e a necessidade de superação e (ou) reconstrução da sociedade capitalista. Gorz foi um dos sociólogos do trabalho mais instigantes das últimas décadas. Sempre atento às transformações sociais, conseguiu, em muitos momentos, sintetizar o que havia de mais profundo e crítico na teoria social.

Em termos gerais, Gorz problematizou e investigou as transformações na produção e na vida social, com o intuito de criticar as formas de exploração e dominação características do capitalismo. Em sua trajetória política e inte-

* Universidade Federal de São Paulo. Programa de PósGraduação em Ciências Sociais. Programa de Pós-Graduação em Serviço Social e Políticas Sociais (UNIFESP).

Estrada do Caminho Velho, 333. Jardim Nova Cidade. Cep: 07252-312. Guarulhos, São Paulo, Brasil. henriqueamorim@hotmail.com

${ }^{1}$ Este artigo é fruto de pesquisa desenvolvida com o apoio do CNPq/PQ. lectual anticapitalista, procurou dar relevo às contradições sociais e descortinar as formas de enfrentamento social e de luta contra as amarras do capital.

Particularmente na França, mas também no Brasil e em outros países, após a morte de Gorz, comentários, artigos, livros e dossiês de revistas foram escritos e organizados a fim de fazer um balanço de sua obra. Entretanto, a obra de André Gorz, atenta a problemas sociais e políticos diversos, é de difícil apreensão. Seja do ponto de vista teórico ou político, seus argumentos se transformavam à medida que a sociedade analisada se alterava, modificando, por consequência, seu projeto político para a sociedade futura. ${ }^{2}$ Há, assim, em Gorz, fruto de sua ousadia teórica, disjunções, rupturas e continuidades - especialmente em relação à temática do trabalho - que acabam por dificultar seu entendimento e, por vezes, sua leitura. ${ }^{3}$

${ }^{2}$ Como sinalizamos, a obra de André Gorz foi analisada e debatida em vários países do ocidente. Sua contribuicão rendeu, assim, muitos livros, teses, dossiês e artigos. Sendo, no entanto, enfadonho citar o conjunto dessas obras sobre o autor, indico duas que parecem descortinar a obra de Gorz de forma ampla. São elas: Silva \& Rodrigues (2006) e Fourel (2009).

${ }^{3}$ Contudo, é importante esclarecer que não se trata de momentos estanques e separados radicalmente. Dentro des- 
Em uma recente biografia escrita sobre André Gorz, publicada em 2016, Willy Gianinazzi destaca três momentos da obra do autor que, para nós, caracterizam três formas distintas de apreensão do trabalho e que, por consequência, fundamentam também distintos horizontes políticos vislumbrados por Gorz.

Nos anos 1960, Gorz viu a justificativa para a autogestão; nos anos 1980, a descentralização, fora do trabalho, do desenvolvimento das capacidades individuais; agora, exatamente depois da metade dos anos 1990, ele descreve um processo de 'intelectualização’ do capital que reduziu a nada o horizonte material de sua reprodução: o comunismo que poderia surgir deste processo seria, portanto, de uma sociedade da inteligência (Gianinazzi, 2016, p. 312).

Autogestão, desenvolvimento do indivíduo fora do trabalho e, por fim, inteligência e conhecimento - sob esses três recortes temáticos, podemos identificar a apreensão do trabalho na obra de Gorz.

É possível expor essa leitura, de maneira sintética, partindo de Estratégia Operária e Neocapitalismo, publicado primeiramente em 1964. Esse livro condensa a busca por uma política autogestionária da classe operária, que se caracterizaria pela retomada do saber-fazer e do controle dos processos de trabalho. Depois, Adeus ao Proletariado: para além do capitalismo (1987), livro no qual a ação política ऽ્ণ operarista e revolucionária é estruturalmente 凶̃ questionada, na medida em que o trabalho na indústria teria deixado de ser o elo de sociabi-

ses momentos da bibliografia gorziana sobre o trabalho, estão presentes encaminhamentos e desenvolvimentos

ک teóricos que claramente nos conduzem ao momento se-

$\supsetneq$ guinte. No entanto, acredito que há, em cada um desses

momentos, uma ruptura a ser explicitada, seja em relação

às suas próprias concepções anteriores, seja em relação às

temáticas postas pelo debate no qual Gorz se inseria. capacidade de colocar em cheque a forma típica de valorização do capital baseada no trabalho imediato. Em todos esses momentos, o trabalho, ou melhor, a percepção de Gorz sobre o lugar social que o trabalho ocupa se condensa como balizadora de suas convicções políticas e de suas elaborações teóricas. ${ }^{4}$

Ao definir e redefinir o lugar do trabalho na sociedade capitalista, André Gorz desenvolve, com isso, um novo conjunto de argumentos e conceitos, isto é, uma nova teoria. No entanto - e aqui me parece estar o problema -, Gorz parece preso, em toda sua obra, a uma mesma problemática analítica, centrada em uma concepção de trabalho limitada ao universo produtivo e determinada por um conjunto de qualificações técnicas e (ou) científicas. Ou seja, Gorz, apesar de ter fundamentado diferentes reflexões sobre a sociedade capitalista, o fez sob o signo de uma mesma problemática sobre o lugar ocupado pelo trabalho.

É, portanto, a apreensão de Gorz sobre a importância que o trabalho ocupa socialmente que está no centro de todo o caminho trilhado pelo autor, na tentativa de analisar os limites do capital e de indicar novas possibilidades para a luta anticapitalista.

Diante dessa pressuposição, o objetivo central deste artigo é problematizar a concepção de trabalho exposta por Gorz em três de suas principais obras: Estratégia operária e neocapitalismo, Adeus ao trabalho e o Imaterial, demonstrando em que medida a teoria social e as alternativas políticas construídas por Gorz mudam vis-à-vis o lugar social ocupado pelo trabalho nessas obras.

Valho-me, assim, de duas questões que orientarão a construção de meus argumentos:

1. De que conceito de trabalho Gorz parte para referenciar sua análise das transformações na produção e na sociedade capitalista? e

\footnotetext{
${ }^{4}$ Neste artigo, me aterei a uma parte da produção bibliográfica de André Gorz. Há artigos e textos em jornais e revistas que demonstram sua prática política em assuntos e temas diversos. Apesar de esses textos serem expressão de suas análises mais densas e de explicitarem sua leitura sobre o trabalho e o capitalismo, sua análise demandaria outro recorte analítico, que não nos propusemos a realizar aqui.
} 
2. Qual o lugar, para Gorz, que o trabalho ocupa na sociedade capitalista, vis-à-vis sua definição de trabalho?

Para responder a essas questões, traçarei o seguinte percurso de exposição: nos dois primeiros itens, retomarei algumas das teses presentes em Estratégia operária e neocapitalismo e em $O$ adeus ao proletariado, procurando descrever o conceito de trabalho de que Gorz parte para apresentar sua estratégia operário-revolucionária nos anos 1960, e depois, nos anos 1980, dar adeus a essa estratégia e ao proletariado. Por fim, no terceiro item, revisitarei O Imaterial, procurando, além de problematizar a concepção de trabalho desenvolvida por Gorz, descrever como as teses ali desenvolvidas se fundamentam em uma mesma problemática analítica presente em Estratégia Operária e Adeus ao Proletariado, isto é, onde passado e presente se encontram como uma manifestação do lugar social ocupado pelo trabalho.

\section{O TRABALHO COMO ESTRATÉGIA}

Em Estratégia operária e neocapitalismo, Gorz (1968a) tem como foco de sua análise, como o próprio título sugere, refletir sobre uma estratégia para a classe operária que lhe permita emancipar-se de seu estado de alienação no trabalho. O ponto central, nesses termos, se caracteriza, como sugere Gorz, por um processo de retomada do controle dos processos de trabalho, via reapropriação dos saberes empíricos perdidos pela classe operária ao longo dos séculos e, sobretudo, no período Taylor-fordista. Esse processo de retomada para um controle então consciente do processo produtivo se fundamentaria como uma forma de "desalienação" do trabalhador em relação a seu trabalho e a si mesmo

Afeito a uma leitura muito em voga entre os partidos comunistas no mundo e também no Partido Comunista Francês - segundo a qual o trabalho seria uma forma de externalização da essência humana, que, no capitalismo, seria es- tranha ao trabalhador, o qual, por consequência, estranharia sua própria essência humana fundada no trabalho -, Gorz fundamenta um projeto político que passa necessariamente pela reconquista dessa essência humana cuja estratégia é retomar o saber-fazer operário como mecanismo central de desalienação. ${ }^{5}$

O objetivo, para Gorz, é recompor o trabalho como algo não estranho ao trabalhador, isto é, como uma atividade vital e emancipadora. Assim, "[...] tudo se passa como se fosse possível reencontrar a substância perdida do ofício através da emergência de uma nova classe operária pós-taylorista” (Artous, 2003, p. 20). A estratégia política traçada por Gorz passava pela humanização do trabalho, pressupondo, assim, que ele teria uma substância positiva a ser reconquistada pelo trabalhador.

Para tal, a reconquista dessa substância perdida deveria ser levada a cabo pelos operários tecnocientíficos, isto é, por aqueles que possuíam maior conhecimento técnico do processo produtivo, os quais, segundo o autor, através da automação, já haviam readquirido parte de seu saber-fazer e, por isso, poderiam dirigir o processo de retomada desse saber-fazer e do controle operário perdidos com o Taylor-fordismo. ${ }^{6}$

A retomada do controle dos processos de trabalho, assim, estaria circunscrita às áreas técnicas e científicas, consideradas cognitivas e fundamentais à valorização do capital. $\mathrm{O}$ aprendizado profissional e o acúmulo de conhecimentos técnicos, empíricos, quantitati-

${ }^{5}$ Essa leitura, apesar de ter sido caricaturada pelos partidos comunistas desde os anos 1930, tem relação com algumas das teses expostas por Marx nos Manuscritos Econômico-Filosóficos (2004), que remetem a uma compreensão essencialista do trabalho, caracterizando-o como fundamento, grosso modo, da natureza humana. Não obstante, com a publicação de A Ideologia Alemã (2005), Marx e Engels superam essa perspectiva humanista de trabalho, adentrando no terreno fundamentalmente histórico para a definição de todos os seus conceitos, isto é, superando qualquer possibilidade de caracterização de alguma atividade, por exemplo, o trabalho, como algo supra-histórico.

${ }^{6}$ Seria preciso retomar a pressuposição, para Gorz (1968, p. 105), do fim da pobreza e das "reformas não reformistas" como um conjunto de reformas que se estruturariam no interior da lógica capitalista, mas que, de alguma maneira, favoreceriam a classe trabalhadora. Discuto este tema mais detidamente em Amorim (2009). 
vos e qualitativos constituiriam a nota de corte entre os trabalhadores que poderiam recompor seus saberes e passar a controlar a produção, e aqueles especializados, que seriam conduzidos pela vanguarda tecnocientífica. ${ }^{7}$

É no primeiro conjunto de indivíduos, no operariado politécnico, que Gorz vislumbra a possibilidade de formação de um sujeito revolucionário. Segundo Gorz, esses saberes acumulados, somados a lutas sindicais politicamente cumulativas, poderiam fazer desabrochar uma consciência política entre os operários tecnocientíficos. Há, portanto, uma clara analogia realizada por Gorz, entre o operariado politécnico e o mestre-artesão.

Ao retomar, com base em uma conciliação de tarefas e técnicas, várias atividades produtivas, o operário tecnocientífico emergiria como um trabalhador pleno e politicamente vigoroso. Nos termos de um processo de desalienação do trabalhador via retomada do processo de trabalho, “... a classe operária reencontraria assim sua substância perdida, em razão disso o domínio de seu trabalho" (Artous, 2003, p. 20). A nova classe operária surgida da automação seria, assim, o sujeito revolucionário que deveria, como uma vanguarda de operários polivalentes, combater o capitalismo monopolista. ${ }^{8}$

A dependência do capital para com esse novo conjunto de trabalhadores multiqualificados daria a esse segmento profissional força política para dirigir um processo reivindicativo, lutando por melhores condições de trabalho, de salário e de vida. Em resumo, Gorz vislumbra um processo de emancipação das amarras do capital, baseado, fundamentalmen-

7 São expressão dessa problemática, além de Estratégia Operária de Gorz, seu outro livro, publicado três anos depois, O Socialismo Difícil (1968b), dois outros livros de Serge Mallet, La Nouvelle Classe Ouvrière (1969) e Le

Pouvoir Ouvrier: Bureaucratie ou Democratie Ouvrière (1971), além do livro de Radovan Richta, Economia Socialista e Revolução Tecnológica (1972), que ilustram a eleição dos operários tecnocientíficos como novos sujeitos

sociais para a retomada do saber-fazer e do controle dos

processos de trabalho em função de suas qualificações

técnicas e científicas. Ver um resumo dessa discussão em Amorim (2009, p. 105-113).

${ }^{8}$ Sobre a temática do capital monopolista, ver o clássico de Braverman (1980). te, em um conjunto de qualificações técnicas adquiridas por parte da classe operária via processo de desenvolvimento de uma racionalidade técnica e científica.

Trata-se, entretanto, de considerar o desenvolvimento das forças produtivas e a automação como síntese desse desenvolvimento e como uma forma de imposição do capital para melhor controlar e intensificar a produção e ampliar a produção de maiores taxas de lucro, ou ver nesse desenvolvimento um processo contraditório, que abriria caminho para a emancipação da classe trabalhadora? Gorz entende que, mesmo não sendo o objetivo das empresas, a dinâmica da automação acabou por constituir um novo tipo de trabalhador mais bem preparado para enfrentar o capital.

Essa tese está temporalmente localizada no final dos anos 1960 na Europa, onde, olhando retrospectivamente, o que estava em jogo para as empresas capitalistas era forçosamente alinhavar a recomposição das taxas de lucro via automação da produção, dada a queda das taxas de lucro que se precipitavam por conta das políticas de distribuição de renda do Estado de bem-estar social, ativadas por lutas trabalhistas. ${ }^{9}$ Com base num objetivo duplo de, ao mesmo tempo em que a produção se incrementava com novas técnicas de gestão empresarial e com a radicalização do fordismo baseada em processos produtivos robóticos e microeletrônicos, procurava-se desconstruir toda a base política partidária e sindical formada ao longo das últimas décadas e maciçamente assentada em instituições trabalhistas ligadas ao operariado industrial.

Acreditar que desse processo surgiria um sujeito histórico revolucionário e capaz de barganhar direitos trabalhistas para o conjunto da classe trabalhadora situa-se como um argumento preso a uma concepção de trabalho essencialista e, também, a um determinismo tecnológico que enxerga, na polivalência e no conhecimento técnico, os meios para a forma-

${ }^{9}$ Sobre o Estado de bem-estar social, ver: Bihr (1998) e Eley (2006). 
ção de uma consciência política classista. ${ }^{10}$

Com isso, Gorz retoma a ideia do trabalhador pleno, através da figura do trabalhador polivalente. Ao fazer isso, ele caracteriza, no contexto da automação, as possibilidades de construção de uma estratégia operária anticapitalista.

Essa é, portanto, a primeira das três reflexões sobre o lugar social ocupado pelo trabalho na obra de André Gorz. Um lugar social central na medida em que Gorz pressupõe o trabalho como fundamento de toda atividade humana. Por isso, o trabalho e os processos de trabalho deveriam ser reumanizados, desalienados pelo operariado politécnico através de um processo de conscientização da classe trabalhadora. Como forma central de luta política contra o capitalismo monopolista, esse processo deveria passar, necessariamente, pela retomada do saber-fazer e do controle dos processos de trabalho perdidos.

Contudo, o operário polivalente, completamente adaptável à realização de múltiplas e variadas tarefas e profundamente subordinado à lógica da produção robotizada, ${ }^{11}$ não poderia cumprir a tarefa política que Gorz a ele destinava por, pelo menos, dois motivos. Primeiro, por conta, como já mencionamos, da completa e irrestrita subordinação do operário multitarefeiro aos novos processos de trabalho e de controle produtivos. Segundo, porque tais técnicas e tecnologias são interessadas, isto é,

${ }^{10}$ Isso parece se dar por conta de um aprisionamento de Gorz à tese do primado das forças produtivas, isto é, a uma concepção de que o desenvolvimento das forças produtivas, principalmente o desenvolvimento técnico-científico, poderia ser colocado a serviço da classe trabalhadora. Resumidamente, as teses de Gorz se fundamentam na indicação de que: "A automação parecia ter sido capaz de forjar um messias da classe trabalhadora. No entanto, esse messias provinha do desenvolvimento técnico e científico que atendia diretamente aos interesses capitalistas em presenca. O desenvolvimento das forcas produtivas teria realizado um efeito duplo: primeiro, foi capaz de 'enxugar' o número de operários nas fábricas e ainda aumentar as taxas de mais-valia relativas a partir da intensificação da produção e do aumento da produtividade dado pelo incremento tecnológico da produção robotizada; segundo, desse desenvolvimento as transformações tecnológicas teriam requisitado, por conta de sua aplicacão, um novo tipo de trabalhador. Este seria, fundamentalmente, um operário que pensasse a produção e que, por isso, pudesse com base em sua resistência corporativa criar as bases para uma luta política ampliada”(Amorim, 2009, p. 107).

${ }^{11}$ Sobre o modelo toyotista, a robotização e a automação da produção, ver: Malagutti (1996) e Gounet (2001). foram constituídas com o objetivo de aprofundar a racionalização e a subordinação do trabalho, não permitindo ao trabalhador uma leitura ampliada do processo de produção. ${ }^{12}$

Do ponto de vista material, essas técnicas não podem ser consideradas neutras. Muito pelo contrário, elas expressam a luta de classes no interior da produção de mercadorias, pois se fundamentam prioritariamente pelos interesses do capital. Ou há alguma dúvida de que o capital, as empresas capitalistas, que implementaram a automação e as novas formas de controle produtivo no estilo do toyotismo foram vitoriosas em relação às classes trabalhadoras nos últimos quarenta anos? Assim, nem o artesão da manufatura, nem o operário polivalente da automação podem desenvolver uma consciência política classista por conta de seus atributos técnicos. Isso seria limitar toda a experiência dos trabalhadores e seus modos de vida a dispositivos produtivos e a qualificações profissionais, saberes empíricos, científicos ou técnicos. ${ }^{13}$

A caracterização desse processo como uma atividade cujo objetivo é "desalienar" o trabalhador tem como pano de fundo, como já observamos, a ideia de humanização dos processos produtivos. ${ }^{14}$ Mais do que isso, ela

${ }^{12} \mathrm{O}$ conjunto de técnicas produtivas não se constituem ao largo das contradições sociais; elas, na verdade, são expressão da dominação e da exploração de classe. Isto é, identificar nelas a possibilidade de uma libertação seria considerá-las dentro de um universo alheio aos interesses sociais hegemônicos na história do capitalismo. Não há nada no desenvolvimento técnico ou científico que, por si só, tenda a libertar o trabalhador das amarras do capital. A introdução de novas forças produtivas se expressa e se condensa, assim, como fundamento da luta de classes na produção. Sobre o tema, ver: Bettelheim (1976) e Magaline (1977).

${ }^{13}$ Ver sobre a questão da cultura de classe, Savage (2004), sobre a questão da experiência que nos remete a cultura do cotidiano, ver Thompson $(1987,2001)$ e, sobre o modo de produção como modo de vida, ver: Gramsci (2004).

${ }^{14}$ Um retorno à constituição da sociologia do trabalho francesa seria interessante para observar como a questão da humanização do trabalho foi pensada nos anos 1940 e 1950. Georges Friedmann e Pierre Naville (1964) foram uns dos primeiros a identificar o trabalhador artesão como sujeito histórico da ruptura com o capitalismo. A retomada da consciência de classe perdida pelo artesão com base na reapropriacão dos saberes empíricos e, depois, dos meios de produção é caracterizada como fundamento para a revolução socialista. Desenvolvi mais detidamente este tema em: Amorim (2006) no sentido de caracterizar este retorno teórico ao artesão, definido de forma ideal-típica, como um estágio prévio ao socialismo. Assim, para estes autores, $\mathrm{e}$ incluindo Gorz de Estratégia operária, tratava-se de 
tem como base a ideia de que a separação entre concepção e execução do trabalho seria a fonte de toda a alienação da classe trabalhadora. Assim, Gorz, nos anos 1960, procurou, a todo custo, encontrar um sujeito para realizar esse processo, mesmo que ele fosse fruto das ambições e desejos das empresas capitalistas.

A luta política rumo ao socialismo se reduziria, com isso, a uma luta pela reapropriação do saber-fazer. O operário polivalente seria o sujeito capaz de romper a separação entre concepção e execução do trabalho, sendo a superação da alienação no trabalho o fim de um processo que tem como meio a recomposição de um conjunto de saberes técnicos. Nesses termos, o "neocapitalismo" apresentou-se, para Gorz, como antessala da revolução socialista, como momento pedagógico para que uma passagem não violenta ao socialismo fosse construída.

Com o desenrolar dos anos 1970 e com a conjuntura política, econômica e produtiva que se apresentava no Japão, na Europa e nos Estados Unidos, onde se via claramente uma radicalização das formas de controle e de intensificação da produção, com larga implementação da automação e da microeletrônica, amparadas pela constituição de políticas estatais neoliberais que davam segurança jurídica e ideológica para o desenvolvimento dessas స्. práticas produtivas, evidenciava-se a incapaci$\stackrel{凶}{\triangle}$ dade de o chamado "operário polivalente" suહं perar a subordinação e a exploração do traba-

\section{O ADEUS AO TRABALHO}

Adeus ao proletariado: para além do socialismo (1987) representa a síntese de um conjunto de teorias sociológicas que já vinham sendo desenvolvidas e expostas desde o início dos anos 1970, mas que se intensificaram ao final dessa década. ${ }^{15}$ Com base em diferentes eixos explicativos, o argumento central que orienta essas teorias é o de que a sociedade industrial teria se esgotado e, em seu lugar, uma sociedade pós-industrial teria emergido. ${ }^{16}$

Na Europa e no Brasil, a publicação de Adeus ao proletariado: para além do socialismo teve forte impacto. Sua recepção no Brasil influenciou, pode-se dizer, muitos intelectuais a reverem seus pressupostos teóricos e políticos, fazendo alguns abandonarem as fileiras do marxismo. Gorz trazia, em sua síntese, algo estonteante. Ele colocava em questão as teses centrais que boa parte do marxismo europeu, do Brasil e da América Latina como um todo, aquele influenciado pelas práticas políticas dos grandes partidos comunistas, haviam chancelado como inquestionáveis no âmbito da sociedade capitalista.

Com a redução relativo do número de postos de trabalho nas indústrias dos países centrais da Europa ocidental, dos Estados Unidos e do Japão, mostrou-se óbvio que as teses que sustentavam a problemática do "paradigma produtivo" haviam de ser postas em cheque. Essa redução do trabalho tipicamente manual-fabril pareceu, aos olhos de alguns pesquisadores europeus e de Gorz, um pro-

${ }^{15}$ Não me estenderei na caracterização dessas teorias. No entanto, em conjunto, elas passam a reivindicar, com mecanismos conceituais distintos, modelos de sociedade que emergiriam dos escombros da chamada "sociedade industrial". Entre esses modelos, podemos indicar: a sociedade do conhecimento com Touraine (1970) e também com Bell (1977); a sociedade pós-materialista com Inglehart (1977); a sociedade da informação com Castells (1999) e Melucci (1980); a sociedade baseada nas atividades intelectuais com Gouldner (1979); e a sociedade de serviços com Offe (1989) e também com Touraine (1989). Há um esboço mais detalhado dessas teorias em Amorim (2015).

${ }^{16}$ Para uma atualização do debate sobre a sociedade pós-industrial, ver a coletânea de textos organizada por Vercellone (2002). 
cesso que se estenderia ao mundo todo (Gorz, 1987, p. 11). ${ }^{17}$ Com isso, a sociedade centrada no trabalho, em valores trabalhistas e constituída por uma sociabilidade vinculada à fábrica (para Gorz, à indústria) teria chegado ao fim e, com o seu fim, o término do sujeito que a ela dava vida: o proletariado.

Gorz concluiu, assim, que o industrialismo teria chegado ao fim e, com ele, o marxismo. Pressupondo a teoria marxista como uma teoria do industrialismo e não do modo de produção capitalista, o autor nos oferece outra forma de pensar a nova sociedade para além do trabalho, para além do antagonismo entre as classes sociais, para além da indústria, vista como local residual - embora ainda necessário para a manutenção social -, para além das instituições políticas típicas da sociedade industrial - como as instituições sindicais e partidárias - e, por fim, para além de convicções e políticas socialistas.

Para fundamentar uma teoria alternativa à teoria marxista, Gorz lança mão do argumento de que o desenvolvimento da racionalidade econômica teria se tornado incontornável. A racionalidade instrumental, sobretudo a econômica, teria se tornado tão poderosa a ponto de não poder ser mais superada. Gorz identifica que tal racionalidade estaria localizada no terreno da produção. Com isso, não seria mais possível que, desse universo produtivo, surgisse qualquer força política capaz de se apresentar como sujeito coletivo anticapitalista. Essa alternativa social e política deveria estar, portanto, em outro lugar.

[...] a verdadeira 'vida' começa fora do trabalho, o trabalho torna-se um meio de ampliar a esfera do

${ }_{17}$ Apesar de a reestruturação produtiva toyotista, que atingiu boa parte do mundo, ter reduzido o número de trabalhadores na indústria a partir dos anos 1970, podemos notar um crescimento relativo do contingente de trabalhadores empregados nesse setor desde 1991 até 2012. Segundo dados da Organização Internacional do Trabalho (OIT, 2014), em torno de 490 milhões de trabalhadores estavam empregados formalmente na indústria em 1991. Já em 2012, esse número sobe para aproximadamente 714 milhões de trabalhadores empregados. Em termos absolutos, há, portanto, no período, um crescimento significativo do número de trabalhadores na indústria, o que parece desabonar a tese do fim do trabalho desenvolvida por Gorz. não trabalho, é a ocupação temporária pela qual os indivíduos adquirem a possibilidade de dar continuidade às suas atividades principais. Trata-se de uma mutação cultural que delineia a passagem para a sociedade pós-industrial. (Gorz, 1987, p. 101)

Com isso, Gorz vislumbra uma fissura na sociedade, isto é, a existência de uma sociedade dual, sendo um dos polos o heterônomo, onde prevaleceriam os valores e as determinações sociais ditados pela racionalidade econômica, versus o polo autônomo, no qual estariam presentes práticas alheias ao trabalho, à produção, ou seja, à racionalidade econômica e, portanto, não contaminadas pela lógica do capital.

Duas figuras são valorizadas nessa indicação de Gorz - o indivíduo e os movimentos sociais -, ambas consideradas alheias, ou predominantemente alheias às imposições da racionalidade econômico-produtiva e, por conta de sua autonomia em relação a essa racionalidade, capazes de constituírem um modo de vida autônomo, isto é, fora da lógica do lucro, da produção racionalizada e do produtivismo.

A segunda das três reflexões sobre o lugar social do trabalho na obra de Gorz (1987, p. 87) tem, portanto, sua força argumentativa sintetizada na noção de "[...] uma não-classe de não-trabalhadores”. O lugar do trabalho é, com isso, deslocado. A positividade atribuída a ele em Estratégia Operária é descartada na medida em que Gorz toma consciência de que o essencialismo humanista de sua concepção de trabalho não fazia mais sentido, e observava o desenvolvimento da racionalidade econômica e a incapacidade de a classe operária superá-la.

Nesses termos, a importância dada ao trabalho e à classe operária, em Estratégia Operária, é agora atribuída aos movimentos sociais situados fora da "esfera do trabalho" e da indústria, isto é, a todo tipo de luta social que não esteja contaminada pela lógica estruturalmente racionalizada da produção de mercadorias. Não obstante, do livro Estratégia Operária permanece a base do raciocínio, a sua problemática. Tanto lá quanto em Adeus ao Proletariado, o que impulsiona a transformação, de 
um operariado politécnico, nos anos 1960, e do fim do trabalho, nos anos 1980, é uma concepção determinista das forças produtivas.

Ao identificar a racionalização da produção, fruto do desenvolvimento das forças produtivas, como um processo inevitável e que teria transformado o trabalho em uma atividade fadada à alienação, Gorz (1987, p. 86) constata que a classe trabalhadora não seria mais capaz de realizar qualquer tipo de revolução. Não obstante, essa mesma racionalidade econômica, pelo desenvolvimento de sua extensão, teria criado, mesmo que contraditoriamente, a possibilidade de economizar tempo de trabalho.

Em Métamorphoses du Travail, Gorz (1988, p. 17-18) deixa essa questão mais clara ao dizer que:

[...] os 'progressos tecnológicos' conduzem, assim, inevitavelmente à questão do conteúdo e do sentido do tempo disponível. Ainda mais: interrogam a natureza de uma civilização e de uma sociedade que valoriza mais o aumento do tempo disponível que o aumento do tempo de trabalho.

A automação e o desenvolvimento das forças produtivas, expressões materiais da racionalidade econômica, teriam provocado, assim, uma economia radical de tempo de trabalho. O avanço tecnológico, com isso, teria levado a sociedade a se dividir. De um lado, A predominaria uma insuperável racionalidade ণิ econômica da produção de mercadorias; de outro, ilhas de autonomia que inspiraram Gorz

ڤं a projetar a ascensão do indivíduo, inserido iี em movimentos sociais, como novo protagonista social.

Gorz, assim como Habermas (1987), ${ }^{18}$ acredita que o lado autônomo, pouco ou não contaminado pela racionalidade instrumental, deve ser preservado e, se possível, dilatado com base em políticas de ampliação da cidadania. Não obstante, tal ampliação está associada, no caso de Gorz mais especificamente,

${ }^{18}$ Há aqui, tanto em Gorz quanto em Habermas, uma forte influência de Weber quanto ao desenvolvimento da racionalidade instrumental: econômica e burocrática. Discuto isso com mais detalhe em Amorim (2009). ao o que fazer como o tempo liberado? Ou ainda, o que fazer com o tempo economizado na sociedade heterônoma? Onde gastá-lo? De que forma?

A despeito de sua ruptura com a teoria marxista, Gorz ainda fundamenta sua análise em um dos mais centrais, e a meu ver o mais equivocado dos argumentos difundidos pelos partidos comunistas, a saber, o do determinismo da economia e das forças produtivas como elementos centrais das transformações estruturais.

O lugar do trabalho, na sociedade capitalista do início dos anos 1980, é, portanto, determinado pelo avanço tecnológico. A semelhança no argumento de fundo é clara. Nos anos 1960, Gorz vislumbrava, no avanço tecnológico, as possibilidades de constituição de um novo sujeito social: o operariado tecnocientífico. Nos anos 1980, esse mesmo desenvolvimento tecnológico teria, por conta de seu forte teor racionalizante, deslocado o trabalho, a produção e seus produtores para um segundo plano social e político.

Assim, a humanização do trabalho via politecnia passa a ser considerada por Gorz um projeto superado em Adeus ao Proletariado, haja vista que:

[...] quaisquer que sejam os esforços dedicados para humanizá-la [a função produtiva], ela permanecerá no essencial uma atividade especializada, que os indivíduos devem cumprir como funções separadas, governadas exteriormente a eles, sob as quais eles não dominam nem o conjunto do processo, nem as suas finalidades. A humanização do trabalho encontra, portanto, um limite ontológico. (Nicolas-Le-Strat, 1996, p. 102-103)

Entretanto, Gorz rompe com Marx ou com uma leitura humanista do trabalho e do lugar social do trabalho desenvolvida por ele mesmo anteriormente? Nossa tese é a de que Gorz não rompe com Marx, mas sim com uma leitura determinista de Marx, à qual ele próprio aderira nos anos 1960. Assim, seu projeto de um trabalhador emancipado dos anos 1960, que poderia se autodeterminar socialmente, por 
conta da retomada do saber-fazer na produção, é superado na medida em que tal projeto é atropelado pelo desenvolvimento tecnológico.

Sua concepção que identificava na atividade-trabalho o meio de toda e qualquer forma de luta anticapitalista é descartada. Gorz simula um descarte de Marx, quando, na verdade, está descartando suas concepções humanistas de trabalho e do lugar que ele ocupa na sociedade capitalista.

Em 1964, em Estratégia Operária e Neocapitalismo, André Gorz pensa que apareceu um novo tipo de produtor capaz de se reapropriar do processo de trabalho à maneira dos antigos artesãos. Enquanto, mais tarde, ele dirá Adeus ao Proletariado, ele vai criticar em Marx aquilo que era, na verdade, sua própria ilusão de ótica. (Artous, 2003, p. 20, grifo do autor)

O processo de humanização do trabalho, almejado por Gorz em Estratégia operária, é, com isso, substituído por práticas políticas que passam pela negação do trabalho, da classe trabalhadora e da produção. Gorz toma, assim, "consciência" de que humanizar a produção e o trabalho não seria possível. Mas, quando percebe a impossibilidade de humanização do trabalho no capitalismo, via operariado politécnico, imputa o equívoco a Marx e não à sua leitura da política e do trabalho.

\section{O TRABALHO DESMEDIDO}

Durante a década de 1980, Gorz aprofunda, com Les Chemins du Paradis, de 1983 e, depois, com Métamorphoses du Travail de 1988, as teses expostas em Adeus ao Proletariado. Já nos anos 1990, em seu livro Misères du Présent, Richesse du Possible de 1997, Gorz se confronta com o desenvolvimento de atividades de trabalho ligadas à informação e ao conhecimento. No entanto, ainda tem reservas em relação à expansão e às possibilidades de emancipação do trabalho via tais atividades, sobretudo por conta da presença cada vez mais ampla da subordinação do trabalho à gestão empresarial e à produção pós-fordista (Giani- nazzi, 2016, p. 318).

Configura-se, não obstante, uma nova inquietação em Gorz nos anos finais da década de 1990, que o levará, mais tarde, em O Imaterial, a projetar formas de emancipação social via apropriação do conhecimento pelo trabalhador. Assim, após dar adeus ao trabalho no início de 1980, ao final da década de 1990 e, sobretudo, com O Imaterial, no início do novo milênio, Gorz retoma o tema do trabalho para desenvolver uma nova compreensão da produção e da sociedade capitalista, deslocando, mais uma vez, o lugar que o trabalho ocupa socialmente. ${ }^{19}$

Apesar de não ser o precursor do debate sobre o trabalho imaterial ${ }^{20}$, Gorz avançou em problemas de pesquisa que até hoje se fazem presentes em produções acadêmicas sobre as novas configurações do trabalho e sobre o trabalho imaterial como principal força produtiva do capitalismo contemporâneo. Entretanto, é possível notar, em $O$ Imaterial, argumentos e previsões sobre o desenvolvimento do trabalho imaterial que não se realizaram ou se realizaram parcialmente, sendo superados, parcial ou integralmente, por novas formas de controle e de exploração que remetem muito mais à reprodução social de antigas formas de organização e de controle tayloristas do que a novas configurações da produção que caracterizariam um processo de autonomização e libertação social do trabalho e do tempo de trabalho.

Ao retomar a discussão sobre o trabalho no capitalismo, via trabalho imaterial, como um dos mecanismos-chave de compreensão da realidade social, Gorz retoma também Marx. No entanto, a retomada de Marx se dá via Grundrisse (2002). ${ }^{21}$

${ }^{19} \mathrm{O}$ otimismo de Gorz frente às novas tecnologias da informação, sobretudo em relação à internet, parece fazê-lo ver, no trabalho imaterial, algo fundamentalmente novo e paradigmático. Em suas palavras: "O computador aparece como o instrumento universal, universalmente acessível, por meio do qual todos os saberes e todas as atividades podem, em princípio, ser partilhados" (Gorz, 2005, p. 21).

${ }^{20}$ Ver, por exemplo, os textos de Lazzarato (1992, 1993), Negri (1992) e Negri e Vincent (1992).

${ }^{21}$ Apesar de Gorz ter feito referência aos Grundrisse de Marx já em Estratégia Operária e Neocapitalismo, sua reto- 
Os Grundrisse de Marx são rascunhos elaborados como preparação da redação d' $O$ Capital (1998). Marx desenvolveu certos aspectos de sua análise que acabaria, mais tarde, deixando de fora d'O Capital. Em partes desses rascunhos, Marx leva ao limite algumas teses, retirando-as, podemos dizer, da história. Isto é, Marx desenvolve alguns pressupostos analíticos como um exercício lógico.

Pensemos, por exemplo, se as forças produtivas fossem desenvolvidas ao limite de nosso raciocínio, ao limite do que hoje poderíamos vislumbrar. Nesse exercício, deixaríamos de lado (porque se trata apenas de um exercício lógico, como se estivéssemos operando com universais abstratos) as contradições sociais, como, por exemplo, a contradição entre capital e trabalho. ${ }^{22}$

Ao fim e ao cabo desse raciocínio lógico, chegaríamos à seguinte constatação: o desenvolvimento da técnica e da ciência levado ao limite e aplicado à produção de mercadorias reduziria drasticamente o tempo de trabalho; tão drasticamente que o tempo livre, fora do trabalho, passaria a orientar a organização da vida em sociedade. Portanto, a sociedade não estaria mais submetida ao tempo de trabalho necessário e, por consequência, à lógica de valorização do capital e passaria a ser governada $\wedge$ pelo tempo livre.

i trabalho imaterial. Faço uma discussão mais detalhada da

เo retomada dos Grundrisse em Amorim (2009, 2013, 2014).

เ Ver também, sobre os Grundrisse, Dussel (2011).

† 22 Resumidamente, entendo que a tendência de

2 diminuição radical do tempo de trabalho com base no

$\underset{\infty}{-}$ desenvolvimento das forças produtivas, exposta por Marx

¿ nos Grundrisse, só teria pertinência em uma sociedade na

- qual esse objetivo estivesse colocado como um objetivo

คे primeiro, isto é, em uma sociedade em que a substituição

$>$ da produção capitalista pela comunista fosse um norteador

ثิ central. Nesse sentido, entendo, como já sublinhei, que se

trata apenas de um exercício lógico de Marx, que projeta

$\stackrel{\pi}{\geq}$ a redução do tempo de trabalho em níveis estruturais

స్ (Amorim, 2009). Como o próprio Marx indica em outras

obras, trata-se, fundamentalmente, de considerar as

IJ contradições sociais em presença. Não faria sentido

ک algum, dessa forma, pensar um desenvolvimento social

a automático, que jogasse pelos ares todo o empreendimento

burguês, já que quem dirige e orienta o desenvolvimento

científico e tecnológico é a própria classe capitalista via

instituições públicas e privadas. tradição central que opera no modo de organização capitalista de produção de mercadorias, presente em Marx, as classes sociais estariam superadas, e uma sociedade do tempo livre se constituiria como consequência dessa nova lógica produtiva.

Esse é, grosso modo, o raciocínio teórico que Marx desenvolve em aproximadamente trinta páginas dos Grundrisse e que, a partir do início dos anos 1990, começou a influenciar autores como Lazzarato (1992, 1993), Negri (1992, 1993), depois Gorz (2005), Moulier-Boutang (2007), entre outros.

Os eixos centrais da discussão, que acabou por configurar o debate sobre o trabalho imaterial, estão ligados, assim, a três conceitos norteadores:

1. o valor-trabalho;

2. o tempo de trabalho; $\mathrm{e}$

3. as classes sociais.

Essas trinta páginas dos Grundrisse são revisadas minuciosamente pelos autores acima indicados, vis-à-vis o desenvolvimento das formas de trabalho informacional e comunicativa, sob o impulso do desenvolvimento da automação e da microeletrônica, para demonstrar como a nova realidade produtiva teria colocado em xeque a teoria marxista.

Assim, os Grundrisse de Marx são retomados com um objetivo duplo. Ao mesmo tempo em que servem de fundamentação teórica para compreender as novas formas de produção chamadas cognitivas, servem também de base teórica para colocar a própria análise marxiana em xeque. Isto é, Marx estaria certo, mas apenas nas trinta páginas que não publicou. O restante de sua teoria teria sido importante para entender a produção industrial típica até os anos 1970. No entanto, depois disso, isto é, com o fim da sociedade industrial, a teoria marxiana estava superada. Os Grundrisse servem aos autores da economia do conhecimento, portanto, como fundamento teórico para a desconstrução da própria obra de Marx. Em Gorz (2005, p. 9), essa desconstrução passa pela fundamentação da tese de que 
o valor não poderia mais ser medido, já que o tempo de trabalho, medida do valor, não seria mais expressão das atividades cujos conteúdos centrais são o "componente comportamental" e a "motivação". Pressupõe-se, assim, que, para a indústria produtora de mercadorias físicas, essa medida era possível, mas agora, para as indústrias que produzem mercadorias não físicas, essa mensuração não seria possível. ${ }^{23}$

A impossibilidade da mensuração é marcada, assim, pela especificidade dos conteúdos do trabalho imaterial. O conjunto desses trabalhos seria uma expressão não mais de capacidades quantitativas que poderiam ser somadas como unidades de produção, mas de um conjunto de trabalhos imensuráveis, que dariam, portanto, origem a um "capital humano” (Gorz, 2005, p. 15-27).

Mas qual seria, para Gorz, a diferença entre mercadorias físicas e não físicas, se elas são produzidas, em geral, em termos de redução do tempo de trabalho com aumento de produtividade? A reposta de Gorz é a de que o conhecimento e a informação não poderiam ser limitados à forma valor, pois não podem ser medidos com base no tempo de trabalho. É, portanto, a imensurabilidade do trabalho imaterial que permite a Gorz desenvolver todo seu arsenal conceitual e vislumbrar "o comunismo do saber" como alternativa à lógica de valorização do capital (Gorz, 2005, p. 59).

No entanto, o movimento que teria criado as condições sociais para a emergência da economia do conhecimento é um velho conhecido de Gorz. O desenvolvimento das forças produtivas (aqui ciência e tecnologia), em seu movimento aparentemente automático, se apresenta, para Gorz, como o sujeito por trás

${ }^{23}$ Gorz pressupõe aqui uma medida aritmética do valor-trabalho. Assim, entende que para a produção de mercadorias físicas, a mensuração é possível; já para a produção de mercadorias não físicas, não seria possível. Marx, contrariamente, caracterizou uma relação de proporcionalidade entre horas necessárias à produção e quantidades de mercadorias produzidas. Trata-se de algo socialmente determinado e que é fruto do embate entre as classes sociais no processo social de repartição da riqueza. Não há, assim, a possibilidade de caracterizar a teoria do valor-trabalho como uma teoria contabilística ou como uma teoria econométrica do tempo de trabalho. do sujeito.

A independência que a produção imaterial acabaria por construir frente às formas tradicionais de valorização do capital seria fruto do próprio desenvolvimento tecnológico que, em sua contradição, teria dado, digamos, um tiro no próprio pé. Outra vez, é nesse conjunto de forças produtivas, análogas àquelas que teriam forjado o operariado tecnocientífico dos anos 1960, e a não classe nos anos 1980, e que tanto nesses outros momentos, quanto no início do século XXI se orientam no sentido de valorizar o capital, que Gorz observa a constituição de ilhas tendenciais de libertação do trabalho das amarras do capital. ${ }^{24}$

Esse processo de "êxodo" da sociedade do tempo de trabalho ${ }^{25}$ para uma sociedade da abundância de tempo seria expressão da diminuição do trabalho imediato e de sua substituição por trabalho imaterial, não determinado pelo tempo de trabalho. O capitalismo entraria, portanto, em uma crise estrutural, determinada por uma "[...] economia em que a produção, requerendo cada vez menos trabalho imediato, distribui cada vez menos os meios de pagamento" (Gorz, 2005, p. 37).

Assim, Gorz caracteriza o "êxodo" da sociedade do tempo de trabalho, em O Imaterial, com base em um movimento lógico de expansão da base científica e tecnológica instalada e radicalizada com o desenvolvimento das Novas Tecnologias da Informação e Comunicação (NTIC). A substituição de trabalho vivo por trabalho morto, tratada por Marx como uma contradição em processo, cujo principal condutor é constituído pelos interesses do capital,

${ }^{24}$ As NTIC, em nosso entendimento, podem até viabilizar formas alternativas e politicamente combativas de trabalho, como, por exemplo, de desenvolvedores de softwares autônomos e independentes como o Happydev, o The WaIkingNerds, ou ainda, o Pulpstation na França, que trabalham quando e como querem e que recusam trabalhos que não lhes parecem adequados a seu perfil político. O problema central, contudo, é analisar se essas formas de trabalho são hegemônicas ou podem se tornar hegemônicas no capitalismo. Para uma discussão sobre a "categoria" de não assalariados e a emergência da autonomia do trabalho dessa categoria, ver Bureau e Corsani (2014).

${ }^{25}$ Ver, sobre o tema, Gorz (2007). 
parece mudar de sentido. ${ }^{26}$ Os interesses do capital seriam, para Gorz, atacados pelos dispositivos tecnológicos que ele mesmo, o capital, colocou em prática para recompor e incrementar suas taxas de lucro.

Retomando essa tese central de $O$ Imaterial, em "Pensar o êxodo da sociedade do trabalho e da mercadoria” ${ }^{27}$, o autor anuncia o capitalismo como um "morto-vivo". Entende, portanto, que a revolução microeletrônica teria permitido produzir “... quantidades crescentes de mercadorias com um volume decrescente de trabalho, de modo que cedo ou tarde o sistema deve[rá] se chocar com seus limites internos.”(Gorz, 2007, p. 95-96). Entende, por fim, que o capitalismo constituído nesse processo é um "morto-vivo", pois, em seu processo de autodestruição, acabaria por romper com qualquer medida de compra baseada no trabalho, haja vista a diminuição radical do tempo de trabalho no processo produtivo. ${ }^{28}$

Gorz está completamente convencido de que a diminuição do tempo de trabalho travou a sociedade baseada na produção de valor. Ela, segundo o autor, sendo uma mudança radical, fundamenta também uma mudança no paradigma social. Não seria mais possível falar em sociedade do trabalho, porque o trabalho (manual) não é mais central na produção,

^ ${ }^{26} \mathrm{Em}$ Marx, esse movimento de substituicão de trabalho จ. vivo por trabalho morto é uma contradição em processo, $\checkmark$ pois é expressão da luta de classes na produção. A utiliza-

( cão de novas tecnologias produtivas com o consequente

尺 descarte de força de trabalho não mais necessário à nova

હं produção é um dispositivo que o capital sempre ativa,

œ mas que tem como freio a resistência da classe trabalha-

î dora. Ou seja, há momentos históricos em que o capital

if consegue avançar mais e outros em que é freado por lutas

เ operárias, sindicais e trabalhistas ligadas ao setor, ao ramo

F produtivo ou à indústria que o capital procura reestrutu-

2. rar. Trata-se, assim, de um enfrentamento político funda-

mentalmente classista, e não um mecanismo imanente ao

œ conteúdo da tecnologia introduzida na produção.

¿. 27 "Penser l'exode de la société du travail et de la marchandise".

$>$

8ే ${ }^{28}$ Assim, a questão central para Gorz (2007, p. 96). é “[...] - como fazer para estabelecer um equivalente monetário

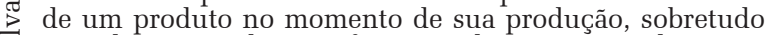
స్ quando esta produção informatizada, automatizada neces- sita de muito pouco trabalho?" A discussão sobre uma ren-

da universal pode ser evidenciada, em muitos de seus tex-

Ư tos, desde os anos 1980. Não entraremos nessa discussão,

- mas tal constatação permite a Gorz encaminhar sua pro-

posta de "Renda Social Garantida", isto é, de uma forma de

distribuição da riqueza produzida que não esteja, porque

S não pode mais estar, vinculada ao tempo de trabalho. pois sua utilização é cada vez mais marginal nos processos produtivos e, por fim, porque o tipo de trabalho (imaterial) que é utilizado na produção não pode ser medido. Seu valor é desmedido.

A terceira e última reflexão sobre o lugar social do trabalho, na obra de Gorz, se localiza, portanto, na retomada positiva do conteúdo do trabalho. Assim como em Estratégia Operária, em O Imaterial, o autor identifica, no conteúdo do trabalho advindo da transformação tecnológica, a chave para explicar a transformação social. No primeiro livro, tratou-se de identificar a polivalência como mecanismo estratégico para a tomada de consciência e de enfrentamento político para a superação da subsunção do trabalho ao capital. Já em O Imaterial, a positividade do trabalho cognitivo está baseada em sua imensurabilidade, vista como mecanismo que iria implodir o capitalismo. O autor considera, portanto, que o tempo de trabalho não seria mais medida do valor na produção imaterial. Como uma tendência automática, esse tipo de trabalho e de produção se colocaria como algoz da produção baseada no tempo de trabalho, configurando, assim, um capitalismo cognitivo. ${ }^{29}$

Na mesma linha de Veltz (2001) e Lazzarato (1992), Gorz examinou, portanto, a questão da medida do tempo de trabalho como questão-chave para compreender a especificidade do trabalho imaterial. Procurou, com isso, determinar o que há de diferente no trabalho imaterial que fundamente sua utilização como mecanismo de quebra do paradigma social, colocando em xeque a "lei do valor-trabalho" como reguladora da produção no capitalismo.

Há, assim, a apreensão do trabalho imaterial como um trabalho cognitivo que não pode ter suas tarefas prescritas e formalizadas. Segundo Gorz, o que o capital demanda não pode ser mais codificado em tarefas rotinizadas na produção imaterial, pois constitui expressão da subjetividade do trabalhador. Assim, o núcleo dessa

${ }^{29}$ Sobre a questão do capitalismo cognitivo, ver Vercellone (2009) e Moulier-Boutang (2007). 
produção seria o "discernimento", a "capacidade de enfrentar o imprevisto" e de "identificar e resolver problemas" (Gorz, 2005, p. 18).

$\mathrm{O}$ argumento de Gorz repousa, com isso, na descrição de uma diferença estrutural entre as formas de organização das indústrias anteriores e essa da produção imaterial. Segundo Gorz (2005, p. 17), é nas capacidades expressivas e cooperativas - segundo o autor, que não podem ser ensinadas, pois fazem parte de uma "cultura do cotidiano"- que está a grande diferença entre os trabalhadores da manufatura e da maquinofatura e aqueles das indústrias pós-fordistas. Segundo Gorz (2005, p. 18), os trabalhadores taylorizados são:

[...] operacionais depois de serem despojados dos saberes, das habilidades e dos hábitos desenvolvidos pela cultura do cotidiano, e submetidos a uma divisão parcelada do trabalho. [...] Era necessário conseguir que o trabalhador executasse, com a regularidade de um autômato, e sem questionar, o comando que a maquinaria industrial lhe transmitia, impondo-lhe a velocidade e a cadência dos atos a executar. Os trabalhadores pós-fordistas, ao contrário, devem entrar no processo de produção com toda a bagagem cultural que eles adquiriram nos jogos, nos esportes de equipe, nas lutas, disputas, nas atividades musicais, teatrais, etc. É nessas atividades fora do trabalho que são desenvolvidas sua vivacidade, sua capacidade de improvisação, de cooperação.

$\mathrm{O}$ autor parece, portanto, entender que haveria uma propriedade específica no conhecimento e na informação que limitaria sua apreensão, utilização e exploração pelo capital. E o mais curioso dessa argumentação, que é por certo arguta e profunda, é a ausência de uma análise mais detalhada da utilização do trabalho, ontem e hoje, do ponto de vista das necessidades do capital. Assim, o aprendizado e a formação do trabalhador, que Gorz coloca no centro da produção imaterial e que, dentro de sua argumentação, não poderiam ser racionalizados, sempre estiveram à disposição do capital para serem ou não utilizados. A cultura do cotidiano sempre fez parte da vida da classe trabalhadora, ${ }^{30}$ a qual, sempre que pôde, de-

${ }^{30}$ Além das mesmas referências da nota 13, ver Popinigis senvolveu atividades fora do trabalho, atividades lúdicas, esportivas, artísticas, ou ainda de qualificação para o trabalho. No entanto, tais atividades não foram, ou foram muito pouco apropriadas pelo capital. Isto é, na produção capitalista, que procurou, ao longo dos séculos, diminuir a autonomia e a participação do trabalhador coletivo nos processos decisórios e de organização do trabalho, particularmente com a radicalização desse processo, com a introdução de práticas gerenciais e de produção taylor-fordistas, o aprendizado fora do trabalho não foi alvo da produção capitalista.

Naquele momento histórico, ao capital nada mais bastava que adestrar o trabalhador para o trabalho parcelar, seriado e repetitivo, mas também regrando sua conduta fora da empresa. ${ }^{31}$ Com isso, a cultura do cotidiano, apesar de sempre estar ali presente, não era requisitada como um instrumento, uma qualificação, uma técnica, um mecanismo que servisse ao processo de valorização do capital. Bastava ao capital o trabalho predominantemente manual, rotinizado e seriado, sem a intervenção do trabalhador coletivo no trabalho de elaboração dos processos de produção, predominando, portanto, um trabalho sem participação direta do trabalhador e sem autonomia produtiva.

No entanto, isso não quer dizer que, na história da produção de mercadorias no capitalismo, incluindo o período chamado taylorfordista, culturas operárias fora da fábrica não existissem. Os conjuntos de trabalhadores, em formações sociais diversas, estavam ali como sujeitos de sua vida, desenvolvendo, na sua (2015).

31 No brilhante Caderno 22: "Americanismo e fordismo", Antonio Gramsci (2011) demonstra como a produção taylor-fordista vai além de um conjunto de técnicas gerenciais e produtivas. $\mathrm{O}$ autor enfatiza como a constituição de um novo tipo de trabalhador passa substancialmente por sua conformação psicofísica dentro e fora da indústria. A rotinização dos processos de trabalho, atingem a vida do trabalhador, na medida que seus hábitos, rotinas e práticas sociais são modelados e sintetizadas em um novo modo de vida. A produção taylor-fordista é apresentada, dessa forma, como um conjunto de elementos gerenciais, produtivos, mas também e ao mesmo tempo, culturais, políticos e ideológicos que recriam conjunturalmente a subalternização das classes trabalhadoras. 
relação contraditória com o capital, seu modo de vida, nos encontros nos bairros, nas festas populares, nas comemorações esportivas, em resumo, em sua vida cotidiana. Lá estiveram e existiram formas coletivas de organização relacionadas ao modo como determinados grupos de indivíduos - imersos em uma realidade comum, de bairros comuns, festas comuns, gostos comuns, trabalhos comuns - desenvolvem, criam ou constituem suas próprias vidas.

A questão está, contrariamente ao que sugere Gorz, em como se organiza a relação entre capital e trabalho, isto é, em como empresas capitalistas e trabalhadores, em formações sociais variadas, sintetizam esse enfrentamento, essa relação de força, essa contradição social. Se estamos falando de capitalismo, estamos falando ainda da subordinação do trabalho ao capital. No entanto, tal subordinação implica na apreensão de formas históricas de apropriação do trabalho pelo capital. Mesmo não considerando a classe trabalhadora um simples fantoche nas mãos do capital - o que por certo, em inúmeros casos, pode-se constatar empiricamente -, a direção do processo de produção e do conjunto de decisões estratégicas para as sociedades contemporâneas ainda está nas mãos dos grandes empresários e banqueiros.

Para a maioria dos trabalhadores, o trabalho ainda é, em grande medida, determinado 亏ั 凶 e pelo seu movimento de interconcorrência. A economia do conhecimento, além de não se apresentar como um "campo" apartado da produção de valor e fundada no tempo de trabalho, não opera como antígeno que formará uma luta anticapitalista. Assim, ela não pode ser considerada - como Gorz (2007, p. 103) vislumbrou - uma síntese do interesse público.

Por fim, a separação entre produção material e produção imaterial realizada por Gorz, operando no universo dos conteúdos e das qualificações do trabalho, fica restrita à lógica do trabalho concreto. Nesse caso, qualquer tentativa de associação com o tempo de trabalho cai por terra, na medida em que trabalhos distintos - por terem propriedades absolutamente diferentes - não podem ser trocados. Isto é, não são intercambiáveis.

Gorz considera, assim, a materialidade do trabalho como fisicidade do trabalho e a imaterialidade do trabalho como não fisicidade do trabalho. Essa pressuposição toma, assim, o materialismo histórico desenvolvido por Marx como um materialismo das coisas físicas e não das relações sociais, na medida em que imputa a Marx a caducidade e a incapacidade de dar conta da produção imaterial.

O entusiasmo de Gorz em relação à economia do conhecimento acaba por levá-lo, mais uma vez, a tomar o trabalho como algo positivo, mas agora por conta de sua natureza imaterial, que passaria a ser expressão de novos modos de vida antagônicos ao modo de vida burguês. O lugar social do trabalho, em O Imaterial, ganha, outra vez, positividade, mas tal positividade vem também, outra vez e finalmente, marcada pelo fetiche das novas tecnologias da informação e da comunicação.

\section{CONCLUSÃO}

Errante em sua tentativa de vislumbrar um sujeito político da luta anticapitalista mesmo que, em certos momentos, esse sujeito fosse um não sujeito -, Gorz não superou a estrutura da concepção de trabalho de seus primeiros livros. Uma concepção de trabalho que ora o percebia como um meio de libertação do capital, ora como um mecanismo completamente submerso à racionalização econômica; que ora o caracterizava como uma atividade fadada à rotinização, ora como algoz do processo de valorização do capital, haja vista seus conteúdos imateriais. Em todos esses momentos, opera a ideia de que, positiva ou negativamente, é no conteúdo do trabalho que se encontra a chave para a emancipação social.

Nessa concepção de trabalho, estão claras as marcas do essencialismo e do trabalho como uma atividade considerada redentora. 
Sua inclinação em identificar, no trabalho, o lugar ou o não lugar social da política limitou, portanto, a compreensão do modo de produção capitalista, não como um modo de produção histórica da existência humana, mas apenas como um modo de organização técnica e gerencial da produção de mercadorias (físicas ou não físicas).

Humanização do trabalho, fim do trabalho e desmedida do trabalho são, assim, fundamentos da obra de Gorz que nos remetem, necessariamente, a uma compreensão essencialista e conteudista do trabalho, a qual parece não observar as múltiplas determinações sociais que a categoria analítica marxiana de trabalho abstrato carrega. Trata-se de uma categoria analítica que, em sua dimensão dialética, explicita a negação do trabalho concreto, mas que dele não prescinde. Uma categoria que se ampara nas dimensões manual e intelectual do trabalho, mas não as cinde em duas dimensões opostas e indissociáveis.

O desenvolvimento contemporâneo das formas de apreensão, sujeição, espoliação, dominação e exploração sociais do trabalho - seja considerando a predominância do trabalho com conteúdo físico-manual, seja a predominância do trabalho com conteúdo não físico-intelectual - está longe de se desvincular das amarras do tempo de trabalho, isto é, dos interesses das grandes empresas capitalistas imersas na lógica de ampliação do lucro.

Em pesquisas recentes, ${ }^{32}$ pode-se observar - particularmente na indústria de software e de tecnologia da informação, na indústria de telefonia e de teleatendimento, as quais poderiam se remeter, em termos gorzianos, à ampliação da liberdade e à ampliação da autonomia no trabalho - um processo de radical taylorização das

${ }^{32}$ Refiro-me aqui às pesquisas desenvolvidas no âmbito do Grupo de Pesquisa Classes Sociais e Trabalho (GPCT) que nos últimos quatro anos tem se dedicado ao exame empírico de empresas ligadas à produção de conhecimento (sobretudo, software), à montagem de aparelhos eletrônicos com base nas NTICs e à produção de informação em empresas de teleatendimento, como: aFoxconn, o $C P q D$, a IBM, a Matera, a Samsung, a CIET, entre outras. atividades produtivas. ${ }^{33}$ Realizadas em casa ou dentro das empresas, tais atividades obedecem a preceitos de controle virtual de produtividade, a formas de controle de desempenho, de horas trabalhadas e de intensidade produtiva que dispensam a presença do "capataz de fábrica" e do cronômetro, valendo-se, no entanto, de softwares que passaram a realizar tais funções de vigilância e controle.

Não se trata mais de relógios de ponto e de fichas de produtividade, mas de dispositivos virtuais que estabelecem uma intensidade e uma produtividade do trabalho sem precedentes na história da produção de mercadorias no capitalismo. Taylor nunca esteve tão vivo! Seja com base nas formas de gerência virtual, com a ideologia do empreendedorismo, segundo a qual o produtor individual se autocontrola para responder a graus de eficiência e de eficácia estipulados pela interconcorrência capitalista, seja com base na lógica da gerência e da supervisão direta, que ainda são hegemônicas. ${ }^{35}$

Imagino que, ao se deparar com esses processos de extrema taylorização da produção, com graus de racionalização e de intensidade produtiva antes nunca vistos, que contaminaram as atividades pretensamente mais intelectualizadas, se vivo, Gorz nos apresentaria outro adeus ao trabalho. Um adeus baseado, mais uma vez, em sua velha concepção de trabalho.

Recebido para publicação em 05 de junho de 2017 Aceito em 24 de julho de 2017

${ }^{33}$ Seria fundamental observar os trabalhos de Huws (2014) e Fuchs e Mosco (2016), sobretudo, procurando notar em Huws como o processo de taylorização do trabalho imaterial no século XXI se desenvolve em analogia às formas de trabalho presentes no século XX e em Fuchs e Mosco dar atenção ao resgaste das categorias marxianas para a apreensão e compreensão do trabalho, no que o autor nomeia, como era do capitalismo digital.

${ }^{35}$ Por exemplo, nas montadoras de aparelhos eletrônicos da China e em outras partes do mundo, o controle do trabalho e o despotismo fabril (virtual ou presencial) estão presentes. 


\section{REFERÊNCIAS}

AMORIM, $\mathrm{H}$. El fin de las clases sociales en la teoría social brasileña. Revista Estudios Latinoamericanos, México, D.F., v. 35, p. 15-37, 2015.

AMORIM, H. As teorias do trabalho imaterial: uma reflexão crítica a partir de Marx. Caderno $C R H$, Salvador, v. 27, n. 70, p. 31-45, 2014.

AMORIM, H. Teoria social e reducionismo analítico: para uma crítica ao debate sobre a centralidade do trabalho. Caxias do Sul, RS: EDUCS, 2006.

AMORIM, H. O tempo de trabalho: uma chave analítica. Sociedade e Estado, Brasília, DF, v. 28, n. 3, p. 503-518, 2013.

AMORIM, H. Trabalho imaterial: Marx e o debate contemporâneo. São Paulo: Annablume, 2009.

ARTOUS, A. Travail et Émancipation Sociales: Marx et le Travail. Paris: Syllepse, 2003.

BIHR, A. Da grande noite à alternativa: o movimento operário europeu em crise. São Paulo: Boitempo, 1998.

BELL, D. O advento da sociedade pós-industrial: uma tentativa de previsão social. São Paulo: Cultrix. 1977.

BETTELHEIM, Ch. A luta de classes na união Soviética. Rio de Janeiro: Paz e Terra, 1976.

BRAVERMAN, H. Trabalho e capital monopolista: a degradação do trabalho no século XX. Rio de Janeiro: Zahar, 1980.

BUREAU, M.C.; CORSANI, A. Du désir d'autonomie à l'indépendance. Une perspective sociohistorique. La nouvelle revue du travail, [S.1.], n. 5, 2014.

CASTELlS, M. A sociedade em rede. São Paulo: Paz e Terra, 1999.

DUSSEL, E. As quatro redações de O Capital (1857-1880): rumo a uma nova interpretação do pensamento dialético de Marx. In: AMORIM, H.; ÁLIAGA, L.; MARCELINO, P. (Org.). Marxismo: teoria, história e política. São Paulo: Alameda, 2011. p. 29-55.

ELEY, G. Forjando a democracia: a história da esquerda na Europa, 1850-2000. São Paulo: Perseu Abramo, 2006.

FOUREL, C. André Gorz, un penseur pour le XXIe siècle. ^ Paris: La Découverte, 2009.

FRIEDMANN, G. O trabalho em migalhas. São Paulo: i Perspectiva, 1972.

FRIEDMANN, G.; NAVILLE, P. Traité de Sociologie $d u$ के Travail. Paris: Librairie Armand Colin, 1964. v. I e II.

i FUCHS, C.; MOSCO, V. Marx in the Age of Digital if Capitalism. Boston: Brill, 2016.

实 GIANINAZZI, W. André Gorz: Une vie. Paris: La Tecouverte, 2016.

GORZ, A. Penser l'exode de la société du travail et de la $\infty$ marchandise. Mouvements, [S.1.], n. 50, p. 95-106, 2007.

\& GORZ, A. Économie de la connaissance, exploitation des savoirs. Multitudes, [S.l.], n. 15, p. 205-215, 2004.

ثิ GORZ, A. O imaterial: conhecimento, valor e capital. São Paulo: Annablume, 2005.

G GORZ, A. Valeur et Richesse: le divorce, Transversales, [S.l.], n. 3, p. 45-47, 2002.

GORZ, A. Misères du Présent, Richesse du Possible, Paris, Galilée, 2004.

GORZ, A. Métamorphoses du Travail: critique de la raison economique. Paris: Galilée, 1988.
GORZ, A. Les Chemins du Paradis: L'Agonie du Capital. Paris: Galilée, 1983.

GORZ, A. Adeus ao proletariado: para além do socialismo. Rio de Janeiro: Forense, 1987.

GORZ, A. Estratégia operária e neocapitalismo. Rio de Janeiro: Zahar, 1968a.

GORZ, A. Socialismo difícil. Rio de Janeiro: Zahar, 1968b.

GOULDNER, A. El Futuro de los Intelectuales y el Ascenso de la Nueva Clase. Madrid: Alianza Editorial, 1979.

GOUNET, T. Fordismo e Toyotismona civilização do automóvel. Rio de Janeiro: Boitempo, 2001. (Çoleção Mundo do Trabalho).

GRAMSCI, A. Americanismo e fordismo. In: GRAMSCI, A. Cadernos do Cárcere. Rio de Janeiro: Civilização Brasileira, 2011. p. 239-282.

GRAMSCI, A. Cadernos do cárcere. Rio de Janeiro: Civilização Brasileira, 2004.

HUWS, U. Vida, Trabalho e Valor no século 21: desfazendo o nó. Caderno CRH, Salvador, v. 27, p. 13-30, 2014.

INGLEHART, R. The Silent Revolution. Princeton: Princeton University Press, 1977.

HABERMAS, J. Teoria de la Accion Comunicativa. Madrid: Taurus, 1987.

LAZZARATO, M. Le cycle de la production immatériel. Futur Antérieur, [S.1.], n. 16, p. 111-120, 1993.

LAZZARATO, M. Le concept de travail immatériel: la grande entreprise. Futur Antérieur, [S.l.], n.10, p. 5461,1992.

LAZZARATO, M.; NEGRI, T. Travail immatériel et subjectivité. Multitude, [S.l.], 1991. Disponível em: <http:// multitudes.samizdat.net/spip.php?page=imprimer\&id_ article $=474>$. Acesso em: 17 fev. 2014

MAGALINE, A. D. Luta de classes e desvalorização do capital. Lisboa: Moraes, 1977.

MALAGUTI, M. L. A ideologia do modelo japonês de gestão. Ensaios FEE, Porto Alegre, v. 17, n. 1, p. 43-73,1996.

MALLET, S. La Nouvelle Classe Ouvrière. Paris: Éditions du Seuil, 1969.

MALLET, S. Le Pouvoir Ouvrier: Bureaucratie ou Democratie Ouvrière. Paris: Anthropos, 1971.

MARX, K. Manuscritos econômico-filosóficos. São Paulo: Boitempo, 2004.

MARX, K. O capital. São Paulo: Nova Cultural, 1998.

MARX, K. Elementos fundamentales para la crítica de la economia política: Grundrisse/Borrador. Buenos Aires: Siglo Veintiuno Argentina Editores, 2002.

MARX, K. Teses sobre Feuerbach. São Paulo: Hucitec, 1993.

MARX, K.; ENGELS, F. A Ideologia Alemã. São Paulo: Boitempo, 2005.

MELUCCI, A. The new social movements: a theoretical approach. Social Science Information, London, v. 19, n. 2, p. 199-226, 1980.

MOULIER-BOUTANG, Y. Le capitalisme cognitif: la nouvelle grande transformation. Paris: Éditons Amsterdam, 2007.

NEGRI, A. Valeur-Travail: crise e problèmes de reconstruction dans le post-moderne. Futur Antérieur, [S.l.], n. 10, p. 20-36, 1992.

NEGRI, A. République constituante. Futur Antérieur, [S.l.], n. 15, 1993, p. 71-80. 
NEGRI, A.; VINCENT, J.-M. Paradoxes autour du travail. Futur Antérieur, [S.1.], n. 10, p. 5-8, 1992.

NICOLAS-LE-STRAT, Pascal. Travail e constitution du sens à propos d'André Gorz. Futur Antérieur, [S.l.], n. 3536, p. 101-109, 1996.

OFFE, C. Trabalho: a categoria-chave da sociologia? RBCS: revista Brasileira de Ciências Sociais, São Paulo, v. 4, n. 10, p. 6-20, 1989.

ORGANIZAÇÃO INTERNACIONAL DO TRABALHO OIT. Global Employment Trends 2014: supporting data sets. Genève, 2014.

Disponível em: <http://www.ilo.org/global/research/ global-reports/global-employment-trends/2014/ WCMS_234879/lang--en/index.htm>. Acesso em: $20 \mathrm{abr}$ 2017.

POPINIGIS, F. E. P. Thompson e a experiência da classe trabalhadora. In: AMORIM, H.; SILVA, J. B. da (Org.). Classes e lutas de classe: novos questionamentos. São Paulo: Annablume, 2015. p. 163-178.

RICHTA, R. Economia socialista e revolução tecnológica. Rio de Janeiro: Paz e Terra, 1972.

ROLLE, P. Introdução à sociologia do trabalho. Lisboa: A Regra do Jogo, 1978
SAVAGE, M. Classe e história do trabalho. In: BATALHA, C. H. M.; SILVA, F. T. da; FORTES, A. (Org.). Culturas de classe. Campinas: Editora UNICAMP, 2004. p. 26-48.

SILVA, J. P. da.; RODRIGUES, I. J. (Org.). André Gorz e seus críticos. São Paulo: Annablume, 2006.

THOMPSON, E. P. A formação da classe operária inglesa. Rio de Janeiro: Paz e Terra, 1987.

THOMPSON, E. P. As peculiaridades dos ingleses e outros artigos. Campinas: Ed. Unicamp, 2001.

TOURAINE, A. Os novos conflitos sociais: para evitar malentendidos. Lua Nova, São Paulo, n. 17, p. 5-18,1989.

TOURAINE, A. Sociedade pós-industrial. Lisboa: Moraes Editores, 1970.

VELTZ, P. La nouvelle révolution industrielle. Revue $d u$ Mauss, [S.l.], n. 18, p. 67-70, 2001.

VERCELLONE, C. Sommes-nous sortis du capitalisme industriel? Paris: La Dispute, 2002.

VERCELLONE, C. L’Analyse "gorzienne" de l'évolution du capitalisme. In: FOUREL, C. André Gorz, un penseur pour le XXIe siècle. Paris: La Découverte, 2009. p. 77-97. 
THE WORK IN ANDRÉ GORZ: three reflections, one problematic

Henrique Amorim

About ten years ago, André Gorz died, leaving stimulating ideas about the limits and need to overcome or deconstruct capitalist society. Always attentive to social transformations, Gorz came at times to synthesize everything that was deep and critical in social theory. However, it is possible to observe, in his writings, an oscillation concerned to the social place that the labor occupies. The place of labor seems to change in function of the development of the productive forces. Thus, Gorz's analysis of the social movement of labor in capitalist society remains a prisoner of a technological determination and a concept of labor limited by the productive universe of professional qualifications. In this article, I have objective to problematize the conception of labor exposed by Gorz in three of his main works: Worker Strategy and Neocapitalism (1964), Farewell to the Proletariat (1980) and The Immaterial (2003), demonstrating how social theory and political alternatives built By Gorz change visà-vis the social place occupied by labor in these writings.

KeY-words: André Gorz. Labor. Humanism. Mots-clés: André Gorz. Travail. Humanisme. Determinism. Immaterial labor.

\section{LE TRAVAIL CHEZ GORZ: trois réflexions, une problématique}

Henrique Amorim

Il y a environ dix ans, André Gorz est décédé, ayant laissé des idées stimulantes sur les limites et la necessité de supération ou de deconstruction de la société capitaliste. Toujours vigilant aux changements sociaux, Gorz est arrivé, à certains moments, à synthétiser tout ce qui était de plus profond et critique dans la théorie sociale. Cependant, il est possible de voir, dans son ouvre, des oscillations par rapport à la place sociale qu'occupe le travail. La place du travail semble changer en raison du développement des forces productives. Ainsi, l'analyse du mouvement social du travail dans la société capitaliste, réalisée par Gorz, démeure prisonnière d'une determination technologique et d'un concept de travail limité par l'univers productif des qualifications professionnelles. Dans cet article, j'ai pour but de problématiser la conception de travail exposée par Gorz dans trois de ses principaux ouvrages: Stratégie Ouvrière et Neocapitalisme (1964), Adieu au Proletariat (1980) et L’Immatériel (2003), en démontrant dans quelle mesure la théorie sociale et les alternatives politiques, développées par Gorz, changent vis-à-vis de la place sociale occupée par le travail dans ces ouvrages.

Determinisme. Travail Imatériel.

Henrique Amorim - Doutor em Ciências Sociais. Professor Adjunto de Sociologia do Programa de Pósgraduação em Ciências Sociais (UNIFESP-Campos Guarulhos) e do Programa de pós-Graduação em Serviço Social e Políticas Públicas (UNIFESP- Campos Baixada Santista) da Universidade Federal de São Paulo. Publicações recentes: Trabalho Imaterial: Marx e o debate contemporâneo (Annablume/Fapesp, 2009); Valor-trabalho e imaterialidade da produção nas sociedades contemporâneas (Clacso, 2012); Teoria Social e Reducionismo Analítico: para uma crítica ao debate sobre a centralidade do trabalho (EDUSC, 2006); Sociologia hoje (Ática, 2013); e organizou o livro Classes Sociais: novos questionamentos (Annablume/Fapesp, 2015). 